\title{
Preparation and Characterization of $\mathrm{N}$-Halamine-based Antimicrobial Fillers
}

\author{
Revathi V. Padmanabhuni ${ }^{1}$, Jie Luo ${ }^{2}$, Zhengbing $\mathrm{Cao}^{2}$, and Yuyu Sun ${ }^{2,}{ }^{*}$ \\ ${ }^{1}$ Department of Chemistry, University of South Dakota, Vermillion, SD 57069 \\ ${ }^{2}$ Biomedical Engineering Program, University of South Dakota, Sioux Falls, SD 57107
}

\section{Abstract}

The purpose of this study was to demonstrate that the surface of $\mathrm{CaCO}_{3}$ fillers could be coated with an $N$-halamine based fatty acid to make the filler surface organophilic and accomplish antibacterial activity simultaneously, rendering the resulting polymer-filler composites antimicrobial. Thus, a new bi-functional compound, 4, 4 -Dimethyl hydantoin-undecanoic acid (DMH-UA), was synthesized by treating the potassium salt of dimethyl hydantoin (DMH) with 11-bromoundecanoic acid (BUA). Upon chlorination treatment with diluted bleach, DMH-UA was transformed into 3-chloro-4, 4-dimethyl hydantoin- undecanoic acid (Cl-DMH-UA). Alternatively, DMH-UA could be coated onto the surface of $\mathrm{CaCO}_{3}$ to obtain the corresponding calcium salt, 4, 4-dimethyl hydantoin-undecanoic acid-calcium carbonate (DMH-UA-CaCO 3$)$. In the presence of diluted chlorine bleach, the coated DMH-UA on the surface of $\mathrm{CaCO}_{3}$ was transformed into $\mathrm{Cl}-\mathrm{DMH}-\mathrm{UA}$, leading to the formation of Cl-DMH-UA-CaCO 3 . The reactions were characterized with FT-IR, NMR, UV, DSC and SEM analyses. Both Cl-DMH-UA and ClDMH-UA-CaCO 3 were used as antimicrobial additives for cellulose acetate (CA). The antimicrobial efficacy of the resulting samples was evaluated against both Escherichia coli (Gramnegative bacteria) and Staphylococcus aureus (Gram-positive bacteria). It was found that with the same additive content, $\mathrm{CA}$ samples with Cl-DMH-UA-CaCO 3 and Cl-DMH-UA had very similar antimicrobial and biofilm-controlling activity, but the former released less active chlorine into the surrounding environment than the latter.

\section{Keywords}

N-Halamine; mineral filler; antimicrobial additive; biofilm; cellulose acetate

\section{INTRODUCTION}

Microbial contamination of polymeric materials is a global concern and remains one of the most serious challenges in hospital equipment, medical devices, water purification systems, hygienic applications, and food packaging and food storage. ${ }^{1-6}$ Studies have indicated that certain microorganisms can stay alive for more than 90 days on various polymer surfaces, making the contaminated surfaces important sources for cross-contamination and crossinfection. ${ }^{3,4}$ Therefore, there is a clear need to develop antimicrobial polymers to reduce the risk of microbial contamination. To date, a number of antimicrobial polymers have been reported, and some studies have achieved very promising results. ${ }^{7-11}$

The research interest in this lab is $N$-halamine-based antimicrobial polymers. An $N$ halamine is a compound containing one or more nitrogen-halogen covalent bonds that are

\footnotetext{
*To whom correspondence should be addressed. Phone: (605) 367-7776, yuyu.sun@usd.edu.
} 
formed by the halogenation of imide, amide, or amine groups. ${ }^{12}$ The antimicrobial activity of $N$-halamines is attributable to halogen exchange reactions between $N$-halamines and microorganisms, leading to death of the microorganisms. ${ }^{12}$ Unlike inorganic halogens, organic $N$-halamines are more stable, less corrosive, and have much less tendency to generate disinfection byproduct, making them attractive candidates as food and water disinfectants. ${ }^{12}$

Considerable efforts have been devoted to incorporate $\mathrm{N}$-halamine moieties into polymeric materials to achieve antimicrobial effects. Worley and coworkers reported the first polymeric $N$-halamine, poly-1, 3-dichloro-5-methyl-5-(4'-vinylphenyl) hydantoin, which was synthesized by the functional modification of polystyrene. ${ }^{13}$ This covalent binding approach was successfully adopted later by a number of other researchers. ${ }^{14-18} \mathrm{An}$ alternative approach is to use $N$-halamine compounds as antimicrobial additives for polymers. ${ }^{19-25}$ This approach is particularly suitable for the antimicrobial treatment of chemically inert polymers, in which direct covalent binding reactions cannot be easily performed in large-quantity real applications. We first reported a class of hindered aminebased $N$-halamine additives, ${ }^{19}$ and then developed amide-based and melamine-based $N$ halamine additives for antimicrobial treatments of polymers. ${ }^{23}$ The simplicity and applicability are attractive features of the additive approach. Nevertheless, like any other polymer additives, migration and leaching of the $N$-halamine additives could be a concern for long-term application, although in our prior studies, leaching was not observed within one year of storage evaluation. ${ }^{24}$

On the other hand, mineral fillers (such as silica, silicates, and precipitated $\mathrm{CaCO}_{3}$ ) are often mixed with polymeric composite materials to facilitate processing and/or reduce costs. ${ }^{26,27}$ Calcium carbonate is one of the most widely used mineral fillers in the plastic, rubber, and paint industries due primarily to its wide availability and low cost. ${ }^{28,29}$ In order to aid dispersion of the inorganic filler with organic polymers and to promote interfacial adhesion between the polymer matrix and the filler, fatty acids with long alkyl chains (e.g., $\mathrm{C}_{10}-\mathrm{C}_{20}$ ) are often used to treat $\mathrm{CaCO}_{3}$ and render the filler surfaces organophilic. ${ }^{30-32}$

In this study, we therefore synthesized a bi-functional compound, 4, 4-dimethyl hydantoinundecanoic acid (DMH-UA). It was hypothesized that the carboxylic acid group of DMHUA could react with $\mathrm{CaCO}_{3}$ to bring the long fatty acid alkyl chain onto the filler surfaces. Upon chlorination with diluted bleach, the amide bond of the coated DMH-UA could be transformed into $\mathrm{N}$-halamines, producing 3-chloro-4, 4-dimethyl hydantoin-undecanoic acid (Cl-DMH-UA, an amide $\mathrm{N}$-halamine) to render the treated $\mathrm{CaCO}_{3}$ filler (Cl-DMH-UA$\mathrm{CaCO}_{3}$ ) antimicrobial. To our knowledge, such a strategy has never been reported. The current study provided a new potential route to alter the filler surface organophilic and accomplish antimicrobial activity simultaneously.

Both Cl-DMH-UA and Cl-DMH-UA-CaCO ${ }_{3}$ were used as antimicrobial additives for cellulose acetate (CA). Because of its wide availability, low cost, and excellent film- and fiber-forming capability, $\mathrm{CA}$ is one of the extensively used polymers for the fabrication of biomedical devices, membranes, films, fibers, etc., ${ }^{33,34}$ in which antimicrobial activities of the polymers are often desired. The antimicrobial efficacy and biofilm-controlling effects of the resulting CA samples were evaluated against both Escherichia coli (Gram-negative bacteria) and Staphylococcus aureus (Gram-positive bacteria) to fully evaluate the feasibility of the new approach. 


\section{EXPERIMENTAL SECTION}

\section{Materials}

Potassium hydroxide, 5, 5-dimethylhydantoin, and potassium iodide were purchased from Acros Organics (Morris Plains, NJ). 11-bromoundecanoic acid (BUA), CA and Triton X-100 (TX-100) were obtained from Sigma-Aldrich (Milwaukee, WI). Calcium carbonate was purchased from Alfa Aesar (Ward Hill, MA). Clorox ${ }^{\circledR}$ regular bleach was obtained from a local store (titration confirmed that the bleach contained 6.0\% $\mathrm{NaClO}$ ). Other reagents were analytical grade and used as received. Escherichia coli (E. coli; ATCC 15597) and Staphylococcus aureus (S. aureus; ATCC 6538) were obtained from American Type Culture Collection (ATCC).

\section{Instruments}

FT-IR spectra were recorded on a Nicolet 6700 FT-IR spectrometer. ${ }^{1} \mathrm{H}$ NMR study was carried out on a JEOL ECS-400 MHz NMR spectrometer at ambient temperature in deuterated chloroform $\left(\mathrm{CDCl}_{3}\right)$. UV spectra were taken using a Beckman Coulter DU 520 UV/VIS spectrophotometer. SEM images were obtained on a Quanta 450/FEI instrument. Thermal properties of the samples were characterized with DSC-Q200 (TA Instruments, DE) under $\mathrm{N}_{2}$ atmosphere at a heating rate of $10{ }^{\circ} \mathrm{C} / \mathrm{min}$.

\section{Synthesis of DMH-UA}

Briefly, 0.025 mole of DMH was dissolved in $30 \mathrm{~mL} \mathrm{CH}_{3} \mathrm{OH}$ containing 0.03 mole of $\mathrm{KOH}$. The mixture was heated at $60{ }^{\circ} \mathrm{C}$ for $1 \mathrm{~h} .{ }^{21}$ The resulting potassium salt of DMH was dried in a vacuum oven at $60{ }^{\circ} \mathrm{C}$ for three days. The anhydrous salt was then dispersed in $100 \mathrm{~mL} \mathrm{~N}, \mathrm{~N}$-dimethyl formamide (DMF) at $95^{\circ} \mathrm{C}$ for $10 \mathrm{~min}$ with constant stirring. Afterwards, 0.025 mole of BUA was added to the mixture and the reaction was continued for $5 \mathrm{~h}$ at $95{ }^{\circ} \mathrm{C}$ under constant stirring. At the end of the reaction, the formed $\mathrm{KBr}$ was filtered, DMF was evaporated, and the crude product was recrystallized from ethanol. DMHUA was obtained as white powders (melting point: $67.9^{\circ} \mathrm{C}$; yield: $60 \%$ ).

\section{Synthesis of Cl-DMH-UA}

A drop ( $30 \mathrm{mg}$ ) of TX-100 (non-ionic surfactant) was added to $50 \mathrm{~mL}$ of $10 \%$ of chlorine bleach (Clorox) and stirred for $5 \mathrm{~min}$. To this, $1.0 \mathrm{~g}$ of DMH-UA was added and the mixture was vigorously stirred for $2 \mathrm{~h}$ at ambient temperature. The product was filtered, and washed thoroughly with distilled water to remove residual chlorines. The products were filtered and dried in a vacuum oven to constant weights. Cl-DMH-UA was obtained as white powders with a melting point of $74.8^{\circ} \mathrm{C}$ at a yield of $81.4 \%$.

\section{Synthesis of DMH-UA-CaCO 3}

A drop (around $30 \mathrm{mg}$ ) of TX-100 was added to $20 \mathrm{~mL}$ distilled water under constant stirring. To this, $0.2 \mathrm{~g}$ of DMH-UA was added and the mixture was stirred for 5 minutes. Afterwards, $1.0 \mathrm{~g}$ of $\mathrm{CaCO}_{3}$ filler was added, and the mixtures were shaken at $40 \mathrm{rpm}$ at ambient temperature for $2 \mathrm{~h}$. The product was collected with filtration, washed with distilled water, filtered, and dried in a vacuum oven to constant weight.

\section{Synthesis of $\mathrm{Cl}-\mathrm{DMH}-\mathrm{UA}-\mathrm{CaCO}_{3}$}

A drop (around $30 \mathrm{mg}$ ) of TX-100 was added to $50 \mathrm{~mL}$ of $10 \%$ of chlorine bleach (Clorox) and stirred for 5 minutes. To this, $1.0 \mathrm{~g}$ of DMH-UA-CaCO 3 was added and the mixture was stirred at ambient temperature for $1 \mathrm{~h}$. After filtration, the product was washed with distilled water, filtered, and dried in a vacuum oven to constant weights. 


\section{lodometric titration}

The active chlorine content of Cl-DMH-UA and Cl-DMH-UACaCO 3 were determined by iodometric titration. ${ }^{21,23}$ About $0.05 \mathrm{~g}$ of the sample was taken into a flask containing 40 $\mathrm{mL}$ of $\mathrm{CHCl}_{3}$ with $1.0 \mathrm{wt} \%$ acetic acid. $1.0 \mathrm{~g}$ of potassium iodide was added and the mixture was stirred for $30 \mathrm{~min}$ at ambient temperature under $\mathrm{N}_{2}$ atmosphere. The released iodine was titrated with $0.01 \mathrm{~N}$ of $\mathrm{Na}_{2} \mathrm{~S}_{2} \mathrm{O}_{3}$. The percentage of active chlorine was calculated based on the following formula (1), where $\mathrm{Vs}$ and $\mathrm{V}_{0}$ were the final and initial volumes $(\mathrm{mL})$ of $\mathrm{Na}_{2} \mathrm{~S}_{2} \mathrm{O}_{3}$ consumed during the titration, $\mathrm{W}_{\mathrm{s}}$ was the weight of the sample $(\mathrm{mg})$, and $\mathrm{C}_{\mathrm{Na} 2 \mathrm{~S} 2 \mathrm{O} 3}$ was the concentration of the sodium thiosulfate used $(0.01 \mathrm{~N})$. Each test was repeated three times and the average value was reported.

$$
\% C l=\frac{35.5}{2} \times \frac{\left(V_{s}-V_{0}\right)}{W_{s}} \times c_{\mathrm{Na}_{2} \mathrm{~S}_{2} \mathrm{O}_{3}} \times 100
$$

\section{Preparation of polymer films containing Cl-DMH-UA and $\mathrm{Cl}-\mathrm{DMH}-\mathrm{UA}-\mathrm{CaCO}_{3}$}

$\mathrm{CA}$ was used as the model polymer. In the preparation of polymer films, predetermined amounts of Cl-DMH-UA or Cl-DMH-UA-CaCO $\mathrm{C}_{3}$ were added to $5 \% \mathrm{CA}$ solution in $\mathrm{CHCl}_{3}$ and mixture was stirred for $1 \mathrm{~h}$ at ambient temperature. The solution was placed onto glass slides in a fume hood for two days at ambient temperature to evaporate the solvent. The obtained films were further dried in vacuum at ambient temperature to achieve constant weights.

\section{Antimicrobial activity of Cl-DMH-UA and $\mathrm{Cl}-\mathrm{DMH}-\mathrm{UA}-\mathrm{CaCO}_{3}$ in water}

All the microbial studies were performed in a biosafety level-2 hood, and the guidelines provided by the U.S. Department of Health and Human services were followed to ensure lab safety. ${ }^{35} \mathrm{~S}$. aureus was grown in Tryptic soy broth at $37^{\circ} \mathrm{C}$ overnight. The cells were harvested by centrifuge at $6000 \mathrm{rpm}$ for 5 minutes, washed twice with phosphate buffer (PBS), and then re-suspended in PBS to concentrations of $10^{7}-10^{8}$ colony forming units per milliliter $(\mathrm{CFU} / \mathrm{mL})$. A known amount of Cl-DMH-UA or Cl-DMH-UA-CaCO 3 was added to $10 \mathrm{~mL}$ sterilized water, vortexed for $60 \mathrm{~s}$, and sonicated for $10 \mathrm{~min}$ to disperse the compounds. Afterwards, $100 \mu \mathrm{L}$ of the above bacterial solution was added into the $\mathrm{Cl}$ DMH-UA or Cl-DMH-UA-CaCO 3 suspension. The mixture was vortexed for $60 \mathrm{~s}$ and then shaken at $40 \mathrm{rpm}$. After a certain period of contact time, $100 \mu \mathrm{L}$ of this suspension was added to $900 \mu \mathrm{L}$ of $0.03 \%$ sodium thiosulfate solution to quench the active chlorine. The resulting solution was vortexed for $10 \mathrm{~s}$, serially diluted, and each dilution was placed onto nutrient agar plates. After overnight incubation at $37^{\circ} \mathrm{C}$, the CFUs on the plates were counted.

\section{Antimicrobial activity of $\mathrm{Cl}-\mathrm{DMH}-\mathrm{UA}$ or $\mathrm{Cl}-\mathrm{DMH}-\mathrm{UA}-\mathrm{CaCO}_{3}$ in $\mathrm{CA}$ films as additives}

$E$. coli and $S$. aureus were used as model microorganisms to challenge the antimicrobial activity of CA films containing Cl-DMH-UA or Cl-DMH-UA-CaCO ${ }_{3}$. The bacteria were grown in their corresponding broth solutions (Luria-Bertani broth for E. coli and Tryptic soy broth for $S$. aureus) at $37{ }^{\circ} \mathrm{C}$ overnight, harvested, washed with PBS, and resuspended in PBS to $10^{7}-10^{8} \mathrm{CFU} / \mathrm{mL}$, as described above. $20 \mathrm{NL}$ of the bacterial suspension was placed on the surface of a CA film containing Cl-DMH-UA or Cl-DMH-UA-CaCO $3\left(2 \times 2 \mathrm{~cm}^{2}\right)$. The film was then covered with another identical film and $100 \mathrm{~g}$ of sterile weights were placed on the "sandwich" to ensure contact. After a certain period of contact, the films were transferred to $10 \mathrm{~mL}$ of $0.03 \mathrm{wt} \%$ sodium thiosulfate aqueous solution to quench the active chlorine without affecting bacterial growth. ${ }^{19}$ The mixture was vortexed for $60 \mathrm{~s}$ and sonicated for $3 \mathrm{~min}$ to transfer the bacteria into the solution. An aliquot of the resulting 
solution was serially diluted, and $100 \mu \mathrm{L}$ of each dilution was placed onto nutrient agar plates. The plates were incubated and CFUs were counted, as described above. The same procedure was applied to pure $\mathrm{CA}$ films (without $\mathrm{Cl}-\mathrm{DMH}-\mathrm{UA}$ or $\mathrm{Cl}-\mathrm{DMH}-\mathrm{UA}-\mathrm{CaCO}_{3}$ ) to serve as controls. Each test was repeated three times and the average value was reported.

\section{Biofilm-controlling function}

In this study, CA films containing Cl-DMH-UA or Cl-DMH-UA-CaCO $3(1.0 \mathrm{~cm} \times 1.0 \mathrm{~cm})$ were immersed in $1 \mathrm{~mL}$ of PBS containing $10^{7}-10^{8} \mathrm{CFU} / \mathrm{mL}$ of $S$. aureus. The samples were gently shaken at $40 \mathrm{rpm}$ for $30 \mathrm{~min}$ at $37^{\circ} \mathrm{C}$ to facilitate bacterial initial adhesion. Afterwards, the films were taken out of the bacteria solution and gently washed with PBS (3 $\times 10 \mathrm{~mL}$ ). Each film was immersed in a well containing $2 \mathrm{~mL}$ of tryptic soy broth and incubated at $37^{\circ} \mathrm{C}$ for $48 \mathrm{~h}$ for biofilm formation. After incubation, each film was gently rinsed with $0.1 \mathrm{M}$ sodium cacodylate buffer (SCB) and the bacteria were fixed with $2.5 \%$ glutaraldehyde in SCB at $4{ }^{\circ} \mathrm{C}$ for $24 \mathrm{~h}$. After gently washing with PBS, the films were dried through an alcohol gradient method, ${ }^{36}$ sputter coated with gold and observed under scanning electron microscope (SEM). Pure CA films were tested under the same conditions to serve as controls.

\section{Stability study}

To investigate the stability of the chlorines in the $N$-halamine-based films, a eries of CA films $\left(1 \times 1 \mathrm{~cm}^{2}\right)$ containing $5 \mathrm{wt} \%$ of Cl-DMH-UA or Cl-DMH-UACaCO ${ }_{3}$ were immersed individually in $10 \mathrm{~mL}$ of deionized water under constant shaking (40 rpm) at ambient temperature. At specified intervals ( $3 \mathrm{~h}, 6 \mathrm{~h}, 24 \mathrm{~h}, 48 \mathrm{~h}, 72 \mathrm{~h}$ and $120 \mathrm{~h}$ ), the films were taken out and the water was iodometrically titrated to determine the content of released chlorines following the NEMI (National Environmental Methods Index) 4500-Cl B. For each interval, triplicate samples were analyzed and the average value was reported.

\section{RESULTS AND DISCUSSION}

\section{Synthesis and Characterization of DMH-UA and CI-DMH-UA}

As illustrated in scheme 1, DMH-UA was synthesized by the nucleophilic reaction of BUA with the potassium salt of DMH. In this study, BUA was selected as it could bring long fatty acid alkyl chains to DMH, and compared with other bromo fatty acids with even longer alkyl chains, BUA is readily available with low costs. Upon chlorination, the amide group of DMH-UA was transformed into Cl-DMH-UA.

FT-IR analysis was used to characterize the products. Fig. 1 showed the FT-IR spectra of DMH, DMH-UA and Cl-DMH-UA. In the spectrum of DMH, the broad peak centered around $3218 \mathrm{~cm}^{-1}$ could be attributed to $\mathrm{N}-\mathrm{H}$ stretching vibrations, and the $1702 \mathrm{~cm}^{-1}$ and $1770 \mathrm{~cm}^{-1}$ band were caused by imide and amide groups. ${ }^{21}$ Upon alkylation, the C-H stretching vibrations of the alkyl chain were clearly observed at $2851 \mathrm{~cm}^{-1}$ and $2918 \mathrm{~cm}^{-1}$ in the spectrum of DMH-UA. ${ }^{21}$ The peaks at $3284 \mathrm{~cm}^{-1}$ and $3436 \mathrm{~cm}^{-1}$ were assigned to the $\mathrm{N}-\mathrm{H}$ and $\mathrm{O}-\mathrm{H}$ vibrations of DMH-UA. In addition, the carbonyl peaks shifted to 1727 $\mathrm{cm}^{-1}$ and $1732 \mathrm{~cm}^{-1}$, and a new carbonyl band appeared at $1695 \mathrm{~cm}^{-1}$, which must be caused by carboxylic group of the undecanoic acid moiety. After chlorination, the N-H band was transformed to $\mathrm{N}-\mathrm{Cl}$ band. As a result, the band at $3284 \mathrm{~cm}^{-1}$ disappeared (N-H band) and only $\mathrm{O}-\mathrm{H}$ vibration at $3434 \mathrm{~cm}^{-1}$ could be detected.

FT-IR results were further supported by ${ }^{1} \mathrm{H}$ NMR studies, as shown in Fig. 2. In the ${ }^{1} \mathrm{H}$ NMR spectrum of DMH, the methyl protons showed a signal at $1.47 \mathrm{ppm}$, and the imide proton and amide protons could be observed at $8.2 \mathrm{ppm}$ and $5.8 \mathrm{ppm}$, respectively. After the reaction with 11-bromo undecanoic acid, new signals caused by the protons on the alkyl 
chains appeared at $4.0 \mathrm{ppm}(\mathrm{E}), 2.3 \mathrm{ppm}(\mathrm{A}), 1.6 \mathrm{ppm}(\mathrm{B}, \mathrm{D})$, and $1.3 \mathrm{ppm}(\mathrm{C})$. In the ${ }^{13} \mathrm{C}$ NMR spectrum of DMH (Fig. 3), the peaks at $156 \mathrm{ppm}(\mathrm{C} 2)$ and $178 \mathrm{ppm}(\mathrm{C} 4)$ were due to the carbonyl carbons. The signal at $60 \mathrm{ppm}$ could be attributed to the quaternary carbon in the DMH ring and the signal near $25 \mathrm{ppm}$ was attributed to methyl carbons. After reacting with 11-bromoundecanoic acid, a new signal at $174 \mathrm{ppm}(\mathrm{F})$ was observed in the spectrum of DMH-UA, which was caused by the carboxylic carbon. The carbonyl carbon signals shifted to $158 \mathrm{ppm}(\mathrm{C} 2)$ and $180 \mathrm{ppm}(\mathrm{C} 4)$, and the peak at $60 \mathrm{ppm}$ shifted to $64 \mathrm{ppm}$ (C5). The new signals observed in the range of 34-24 ppm (A, B, C, D, E) were attributable to the methylene groups of the alkyl chains, confirming the structure of DMH-UA. Upon chlorination, the signal at $64 \mathrm{ppm}$ (C5) shifted to $65 \mathrm{ppm}$ in the spectrum of Cl-DMH-UA, which might be caused by the replacement of the $\mathrm{N}-\mathrm{H}$ bond by $\mathrm{N}-\mathrm{Cl}$ bond as the latter had stronger electron-withdrawing effect on $\mathrm{C} 5$ than the former. The $\mathrm{N}-\mathrm{H} \rightarrow \mathrm{N}-\mathrm{Cl}$ transformation was further supported by UV analysis. As shown in Fig. 4, the absorption centered at $240 \mathrm{~nm}$ in the spectrum of DMH-UA was caused by the hydantoin ring structures. ${ }^{37-40}$ After chlorination, in addition to the $240 \mathrm{~nm}$ peak, a broad band at 270-280 $\mathrm{nm}$ could be observed, and this was caused by the disruption of the $\mathrm{N}-\mathrm{Cl}$ bond and/or the transition from a bonding to an antibonding orbital of the $N$-halamine structure. ${ }^{19}$

Thermal properties of the samples were examined by DSC, as shown in Fig. 5. According to the supplier, DMH melts at $175-180^{\circ} \mathrm{C}$. In the DSC curves, BUA showed a sharp melting point at $50.5^{\circ} \mathrm{C}$. Upon the alkylation of DMH with BUA, the melting point of DMH-UA appeared at $67.9^{\circ} \mathrm{C}$. These were reasonable findings since the alkylation reaction would reduce the hydrogen-bonding sites of the resulting compound, and the long alkyl chain of BUA would prevent the close pack of the molecules, both of which would reduce the melting point of DMH-UA. Upon chlorination, the N-H bond in DMH-UA was transformed into $\mathrm{N}-\mathrm{Cl}$ bond, making the compound more polar, and the melting point of Cl-DMH-UA increased to $74.8^{\circ} \mathrm{C}$. Furthermore, an exothermal peak at $162.3^{\circ} \mathrm{C}$ was observed, which could be caused by the thermal decomposition of the $\mathrm{N}-\mathrm{Cl}$ bond in Cl-DMH-UA.

\section{Characterization of $\mathrm{Cl}-\mathrm{DMH}-\mathrm{UA}-\mathrm{CaCO}_{3}$}

Iodometric titration showed that under our experimental conditions, Cl-DMH-UA-CaCO 3 had $1.18 \%$ of active chlorines, suggesting that the $\mathrm{CaCO}_{3}$ filler was coated with $36.42 \%$ of Cl-DMH-UA. Fig. 6 showed the FT-IR spectra of the original $\mathrm{CaCO}_{3}$ and Cl-DMH-UA$\mathrm{CaCO}_{3}$. In the spectrum of $\mathrm{CaCO}_{3}$, the peaks at $1420-1470 \mathrm{~cm}^{-1}, 874 \mathrm{~cm}^{-1}$, and $713 \mathrm{~cm}^{-1}$ were attributed to $\mathrm{C}-\mathrm{O}$ stretching and bending vibrations of the carbonate anion $\left(\mathrm{CO}_{3}{ }^{2-}\right){ }^{41}$ After coating with Cl-DMH-UA, in addition to the characteristic bands of calcium carbonate, new bands appeared at 2851 and $2914 \mathrm{~cm}^{-1}$ as well as 1732 and $1795 \mathrm{~cm}^{-1}$, which were attributable to $\mathrm{C}-\mathrm{H}$ stretching vibrations and $\mathrm{C}=\mathrm{O}$ stretching vibrations of the Cl-DMH-UA moieties, respectively.

In DSC studies (Fig. 7), the pristine $\mathrm{CaCO}_{3}$ did not show any significant thermal changes at lower than $250{ }^{\circ} \mathrm{C}$. In the DSC curve of Cl-DMH-UA-CaCO 3 , a melting peak at $75.7^{\circ} \mathrm{C}$ and an exothermic peak at $164.2^{\circ} \mathrm{C}$ were observed, confirming that Cl-DMH-UA was coated onto $\mathrm{CaCO}_{3}$ (see the similarities between Fig. 5 and Fig. 7).

The surface morphology of $\mathrm{CaCO}_{3}$ and Cl-DMH-UA-CaCO 3 was examined by SEM and both of these fillers exhibited scalenohedral calcite morphology (Fig. 8) with particle sizes in the range of $2-4 \mu \mathrm{m}$. No significant morphological change was observed upon coating Cl-DMH-UA onto $\mathrm{CaCO}_{3}$. Nevertheless, the coated $\mathrm{CaCO}_{3}$ fillers became less agglomerate as compared to the uncoated $\mathrm{CaCO}_{3}$, which could be caused by the Cl-DMH-UA moieties on the filler surfaces that prevented closer contact. In previous studies, similar changes were observed when $\mathrm{CaCO}_{3}$ was coated with other organic compounds/polymers. ${ }^{42}$ 


\section{Antimicrobial activities of Cl-DMH-UA and $\mathrm{Cl}$-DMH-UA-CaCO ${ }_{3}$ in water}

The antimicrobial activities of Cl-DMH-UA and Cl-DMH-UA-CaCO ${ }_{3}$ against $S$. aureus in water were summarized in Table I (each test was repeated three times). With only $300 \mathrm{ppm}$ of active chlorine, Cl-DMH-UA provided a total kill of $10^{7}-10^{8} \mathrm{CFU} / \mathrm{mL}$ of $S$. aureus in $120 \mathrm{~min}$. When the chlorine content was increased to $500 \mathrm{ppm}$, the minimum contact time for a total kill of the bacteria decreased to $60 \mathrm{~min}$. On the other hand, Cl-DMH-UA-CaCO showed a much lower antimicrobial potency against the same bacteria. With $500 \mathrm{ppm}$ of active chlorine, Cl-DMH-UA-CaCO 3 only provided a $93 \%$ and $99.5 \%$ of reduction of $S$. aureus after $60 \mathrm{~min}$ and $120 \mathrm{~min}$ of contact, respectively. This lower antimicrobial activity of Cl-DMH-UA-CaCO 3 in water could be caused by contact, i.e., since Cl-DMH-UA was coated onto $\mathrm{CaCO}_{3}$ surfaces, the $\mathrm{N}$-halamine moieties had limited mobility to make full contact with the bacteria, leading to weak antimicrobial potency.

\section{Antimicrobial activities of $\mathrm{Cl}-\mathrm{DMH}-\mathrm{UA}$ and $\mathrm{Cl}-\mathrm{DMH}-\mathrm{UA}-\mathrm{CaCO}_{3}$ in $\mathrm{CA}$ films as antimicrobial additives}

The antimicrobial activities of Cl-DMH-UA and Cl-DMH-UA-CaCO 3 in CA films were summarized in Table II. It was interesting to note that in the tests against $S$. aureus (Grampositive bacteria), the two systems demonstrated very similar antimicrobial efficacy, in contrast to the trend in the water-testing system (see Table I). This could still be explained by contact: in CA films, Cl-DMH-UA could form its own domains ("islands") that were dispersed in the matrix of CA polymers ("sea"), a very similar morphology to the dispersion of Cl-DMH-UA-CaCO 3 ("islands") in CA polymers ("sea"). In the antimicrobial tests, only $N$-halamines on the surfaces of the "islands" could make full contact with $S$. aureus for the chlorine exchange rections, ${ }^{43-45}$ leading to similar antimicrobial potency of the Cl-DMH$\mathrm{UA}$ and $\mathrm{Cl}-\mathrm{DMH}-\mathrm{UA}-\mathrm{CaCO}_{3}$ systems.

On the other hand, in the test against E. coli (Gram-negative bacteria), at $1 \%$ and $3 \%$ of additive contents, CA films with Cl-DMH-UA showed more potent antimicrobial effects than CA films with Cl-DMH-UA-CaCO 3 (Table II).

This difference could be attributed to the different structures of the bacteria. A major structural difference between Gram-negative bacteria and Gram-positive bacteria is that the cell wall of the former is overlaid with an outer membrane comprising lipopolysaccharide. This lipopolysaccharide layer offers a supplementary barrier limiting or preventing the penetration of antimicrobial agents into the cell. ${ }^{46-48}$ Therefore, a slight difference in the level of contact might result in a significant difference in antimicrobial potency against $E$. coli (Gram-negative bacteria). When the additive content was further increased to $5 \%$, the difference became unobvious, and the two systems demonstrated similar potency against $E$. coli.

\section{Biofilm-controlling function}

Biofilm-formation is a serious problem in a broad range of applications. ${ }^{49}$ Since CA films containing Cl-DMH-UA and Cl-DMH-UA-CaCO 3 showed potent antimicrobial effects, it was highly likely that they could also prevent microbial adhesion/biofilm-formation. To evaluate this effect, CA films with or without the new additives were first exposed to $S$. aureus for $30 \mathrm{~min}$, and then incubated in broth solution for $48 \mathrm{~h}$ to facilitate biofilmformation. ${ }^{50}$ As shown in Fig. 9A, on the control CA film surface, a large quantity of bacterial cells aggregated together and formed several layers, suggesting biofilm-formation. However, on CA film surfaces with $5 \%$ of Cl-DMH-UA or Cl-DMH-UA-CaCO 3 (Fig. 9B and Fig. 9C), the microbial adhesion level was much lower, and no biofilms could be observed. The biofilm-controlling function of CA films containing Cl-DMH-UA or ClDMH-UA-CaCO 3 could be attributed to the antimicrobial activities of the $N$-halamines, i.e., 
when bacteria came into contact with the films, most of them were inactivated during and/or after adherence/colonization, resulting in cleaner surfaces. It might also be possible that when bacteria were approaching to the discs, they retreated when they sensed that the surface was inappropriate for adhesion. ${ }^{23}$ More studies are needed to determine the action mode(s) of the samples for the further development of biofilm-controlling materials.

\section{Stability studies}

The stability of chlorines in Cl-DMH-UA and Cl-DMH-UA-CaCO 3 inside CA films was evaluated by immersing the sample films in deionized water. As shown in Fig. 10, after 120 h, CA films with $5 \%$ of Cl-DMH-UA and Cl-DMH-UA-CaCO $\mathrm{C}_{3}$ released $0.57 \mu \mathrm{g} / \mathrm{mL}$ and $0.49 \mu \mathrm{g} / \mathrm{mL}$ of active chlorines into the immersing water, respectively, which were much lower than the current EPA maximum residual disinfectant level of $4 \mathrm{ppm}$ in drinking water ${ }^{51,52}$, pointing to even greater potentials of the new materials.

\section{CONCLUSIONS}

In summary, we have developed an $N$-halamine precursor DMH-UA, which could be coated onto the surface of mineral filler $\mathrm{CaCO}_{3}$. After chlorine bleach treatment, Cl-DMH-UA was formed on $\mathrm{CaCO}_{3}$ surfaces, providing potent antimicrobial effects. In water-based tests, $\mathrm{Cl}$ DMH-UA showed faster antimicrobial effects than the corresponding Cl-DMH-UA-CaCO 3 , primarily because the former had higher mobility than the latter to make full contact with bacterial cells. However, when used as antimicrobial additives in CA films, Cl-DMH-UA and $\mathrm{Cl}-\mathrm{DMH}-\mathrm{UA}-\mathrm{CaCO}_{3}$ provided the resulting films with very similar antimicrobial potency, particularly at higher additive content. Further, CA films with Cl-DMH-UA$\mathrm{CaCO}_{3}$ released less active chlorines into the surrounding environment than the films with Cl-DMH-UA. Although more investigations are needed to further evaluate the long-term stability of the antimicrobial fillers inside CA and other polymeric materials, the findings from the current study suggested that it could be an effective strategy to use $N$-halaminecoated mineral fillers as antimicrobial additives of polymers to achieve potent antimicrobial and biofilm-controlling effects.

\section{Acknowledgments}

This study was sponsored in part by NIH, NIDCR (Grant number R01DE018707). R.V.Padmanabhuni acknowledges the financial support from NSF-EPS-09-0903804 for assistantship.

\section{References}

1. Binder S, Levitt AM, Sacks JJ, Hughes JM. Emerging infectious diseases: public health issues for the 21st century. Science. 1999; 284:1311. [PubMed: 10334978]

2. Larson E, Olmsted RN. Research priorities project, year 2000: the lone ranger rides again. Am J Infect Control. 2001; 29:69. [PubMed: 11287871]

3. Neely AN, Maley MP. Survival of Enterococci and Staphylococci on hospital fabrics and plastic. J Clin Microbiol. 2000; 38:724. [PubMed: 10655374]

4. Scott E, Bloomfield SF. The survival and transfer of microbial contamination via cloths, hands and utensils. J Appl Bacteriol. 1990; 68:271. [PubMed: 2111304]

5. Richards MJ, Edwards JR, Culver DH, Gaynes RP. Nosocomial infections in medical intensive care units in the United States. Crit Care Med. 1999; 27:887. [PubMed: 10362409]

6. Litsky W. Wanted: plastics with antimicrobial properties. Am J Pub Health. 1990; 80:13. [PubMed: 2293796]

7. Cheng Z, Zhu X, Shi ZL, Neoh KG, Kang ET. Polymer microspheres with permanent antibacterial surface from surface-initiated atom transfer radical polymerization. Ind Eng Chem Res. 2005; 44:7098. 
8. Pernak J, Branicka M. Synthesis and aqueous ozonation of some pyridinium salts with alkoxymethyl and alkylthiomethyl hydrophobic groups. Ind Eng Chem Res. 2004; 43:1966.

9. Tiller JC, Liao C, Lewis K, Klibanov AM. Designing surfaces that kill bacteria on contact. Proc Natl Acad Sci US A. 2001; 98:5981.

10. Jayaraman A, Yarmush ML, Roth CM. Molecular bioengineering. Ind Eng Chem Res. 2002; 41:441.

11. Emerson DW. Slow release of active chlorine and active bromine from styrene-divinylbenzene copolymers bearing $\mathrm{N}, \mathrm{N}$-dichlorosulfonamide, $\mathrm{N}$-chloro- $\mathrm{N}$-alkylsulfonamide and $\mathrm{N}$-bromo- $\mathrm{N}$ alkylsufonamide functional groups. Polymer-supported reagents. Ind Eng Chem Res. 1991; 30:2426.

12. Worley SD, Williams DE. Halamine water disinfectants. Crit Rev Environ Control. 1988; 18:133.

13. Worley SD, Sun G. Biocidal polymers. Trends Polym Sci. 1996; 11:364.

14. Sun G, Xu X. Durable and regenerable antibacterial finishing of fabrics: biocidal properties. Text Chem Color. 1998; 30:26.

15. Sun Y, Sun G. Durable and refreshable polymeric $N$-halamine biocides containing $3-\left(4^{\prime}-\right.$ vinylbenzyl)-5, 5-dimethylhydantoin. J PolymSci, Part A: Polym Chem. 2001; 39:3348.

16. Sun Y, Sun G. Synthesis, characterization, and antibacterial activities of novel $N$-halamine polymer beads prepared by suspension copolymerization. Macromolecules. 2002; 35:8909.

17. Worley SD, Li F, Wu R, Kim J, Wei CI, Williams JF, Owens JR, Wander JD, Bargmeyer AM, Shirtliff ME. A novel $N$-halamine monomer for preparing biocidal polyurethane coatings. Surf Coat Int, Part B. 2003; 86:273.

18. Chen Y, Worley SD, Kim J, Wei CI, Chen TY, Santiago JI, Williams JF, Sun G. Biocidal poly(styrene hydantoin) beads for disinfection of water. Ind Eng Chem Res. 2003; 42:280.

19. Chen Z, Sun Y. N-chloro-hindered amines as multifunctional polymer additives. Macromolecules. $2005 ; 38: 8116$.

20. Chen Z, Sun Y. Antimicrobial functions of $N$-chloro-hindered amines. Polym Preprint. 2005; 46:835.

21. Chen Z, Sun Y. N-halamine based antimicrobial additives for polymers. Ind Eng Chem Res. 2006; 45:2634. [PubMed: 18714370]

22. Sun X, Cao Z, Sun Y. N-chloro-alkoxy-s-triazine-based antimicrobial additives: preparation, characterization, and antimicrobial and biofilm-controlling functions. Ind Eng Chem Res. 2009; 48:607.

23. Sun X, Cao Z, Porteous N, Sun Y. Amine, melamine, and $N$-halamines as antimicrobial additives for polymers. Ind Eng Chem Res. 2010; 49:11206. [PubMed: 21088762]

24. Cao Z, Sun Y. Polymeric $N$-halamine latex emulsions for use in antimicrobial paints. ACS Appl Mater Interfaces. 2009; 1:494. [PubMed: 20353242]

25. Luo J, Porteous N, Sun Y. Rechargeable biofilm-controlling tubing materials for use in dental unit water lines. ACS Appl Mater Interfaces. 2011; 3:2895. [PubMed: 21721534]

26. Kiselev AV. Adsorption properties of hydrophobic surfaces. J Colloid Interface Sci. 1968; 28:430.

27. Ferch, Horst. Amorphous synthetic silica products: production and characterization. Chemie Ingenieur Technik. 1976; 48:922.

28. Price GJ, Ansari DM. Surface modification of calcium carbonates studied by inverse gas chromatography and the effect on mechanical properties of filled polypropylene. Polym Int. 2004; 53:430.

29. Thio YS, Argon AS, Cohen RE, Weinberg M. Toughening of isotatic polypropylene with $\mathrm{CaCO}_{3}$ particles. Polymer. 2002; 43:3661.

30. Rothon, RN., editor. Particulate-filled Polymer Composites. Longman Scientific and Technical; Harlow: 1995.

31. Rungruang, Pakpoom; Grady, Brian P.; Supaphol, Pitt. Surface-modified calcium carbonate particles by admicellar polymerization to be used as filler for isotactic polypropylene. Colloids Surfaces A: Physicochem Eng Aspects. 2006; 275:114.

32. Shi, Xuetao; Rosa, Roberto; Lazzeri, Andrea. On the coating of precipitated calcium carbonate with stearic acid in aqueous medium. Langmuir. 2010; 26:8474. [PubMed: 20334413] 
33. Edgar KJ, Buchanan CM, Debenham JS, Rundquist PA, Seiler BD, Shelton M. C Advances in cellulose ester performance and application. Prog Polym Sci. 2001; 26:1605.

34. Fisher, Steffen; Thuemmler, Katrin; Volkert, Bert; Hettrich, Kay; Schmidt, Ingeborg; Fisher, Klaus. Properties and applications of cellulose acetate. Macromolecular Symposia. 2008; 262:89.

35. Richmond, JY.; McKinney, RW. Biosafety in Microbiological and Biomedical Laboratories. 4. U.S. Government printing office; Washington, D.C: 1999. p. 12

36. Cen L, Neoh KG, Kang ET. Antibacterial activity of cloth functionalized with $N$-alkylated poly(4vinylpyridine). J Biomed Mater Res. 2004; 74A:70.

37. Cauletti C, Devillanova FA, Isaia F, Verani G, Vondrak T. Electronic structure of five-membered heterocyclic compounds containing nitrogen, oxygen, sulfur and selenium. Gasphase UV photoelectron spectra and quantum-mechanical calculations. J Mol Struct. 1988; 175:447.

38. Santos E, Rosillo I, Del CB, Avendano C. Determination of $\mathrm{p} K a$ Values for hydantoins by spectrophotometry. J Chem Res Synop. 1982; 5:131.

39. Ajo D, Casarin M, Granozzi G, Poli A, Tondello E. Electronic structure of imides by UV photoelectron spectroscopy and INDO/S calculations: Hydantoin and urazole. J Mol Struct. 1982; 82:277.

40. Uscumlic GS, Kshad AA, Mijin DZ. Synthesis and investigation of solvent effects on the ultraviolet absorptions spectra of 1, 3-bis-substituted-5, 5-dimethylhydantoins. J Serb Chem Soc. 2003; 68:699.

41. Nakamoto, K. Infrared Spectra of Inorganic and Coordination Compounds. John Wiley \& Sons, Inc; New York: 1970.

42. Zhang, Jie; Guo, Jinshan; Li, Tao; Li, Xiaoyun. Chemical surface modification of calcium carbonate particles by maleic anhydride grafting polyethylene wax. Int J Green Nanotech Phy Chem. 2010; 1:65.

43. Bodor N, Kaminski JJ, Worley SD, Colton RJ, Lee TH, Rabalais JW. Photoelectron spectra, hydrolytic stability, and antimicrobial activity of $N$-chlorinated piperidines. J Pharm Sci. 1974; 63:1387. [PubMed: 4214917]

44. Naquib I, Tsao T, Sarathy PK, Worley SD. Kinetic versus thermodynamic control in chlorination of imidazolidin-4-one derivatives. Ind Eng Chem Res. 1991; 30:1669.

45. Block, SS. Disinfection, Sterilization and Preservation. 3. Lea \& Febiger; Philadelphia: 1983.

46. Denyer SP. Mechanisms of action of antibacterial biocides. Int Biodeterior Biodegrad. 1995; 36:227.

47. Russell AD. Mechanism of bacterial resistance to biocides. Int Biodeterior Biodegrad. 1995; 36:247.

48. Denyer SP, Stewart GSAB. Mechanisms of action disinfectants. Int Biodeterior Biodegrad. 1998; 41:261.

49. Stoodley LH, Costerton JW, Stoodley P. Bacterial biofilms: from the natural environment to infectious diseases. Nature Rev Microbiol. 2004; 2:95. [PubMed: 15040259]

50. An, YH.; Friedman, RJ. Handbook of Bacterial Adhesion - Principles, Methods, and Applications. Vol. Chapter 4. Humana Press; Totowa: 1999. p. 53

51. http://water.epa.gov/drink/contaminants/index.cfm\#Byproducts

52. EPA. National Primary Drinking Water Regulations: disinfectants and disinfectants byproducts. Federal Register. 1998; 63:69390. 


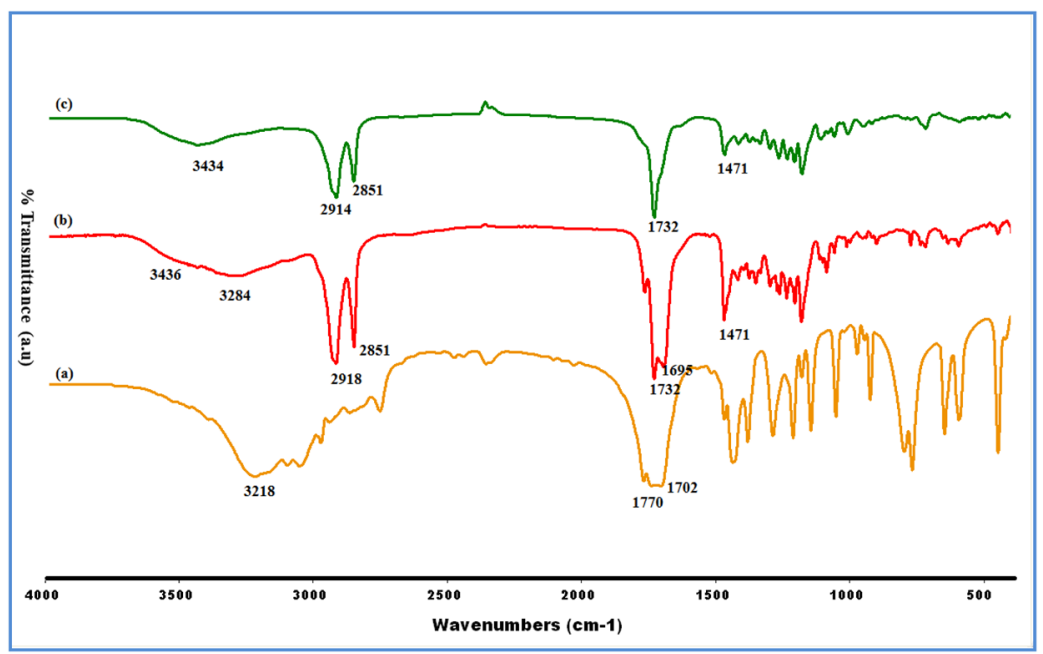

Figure 1.

FT-IR spectra of (a) DMH, (b) DMH-UA, and (c) Cl-DMH-UA 


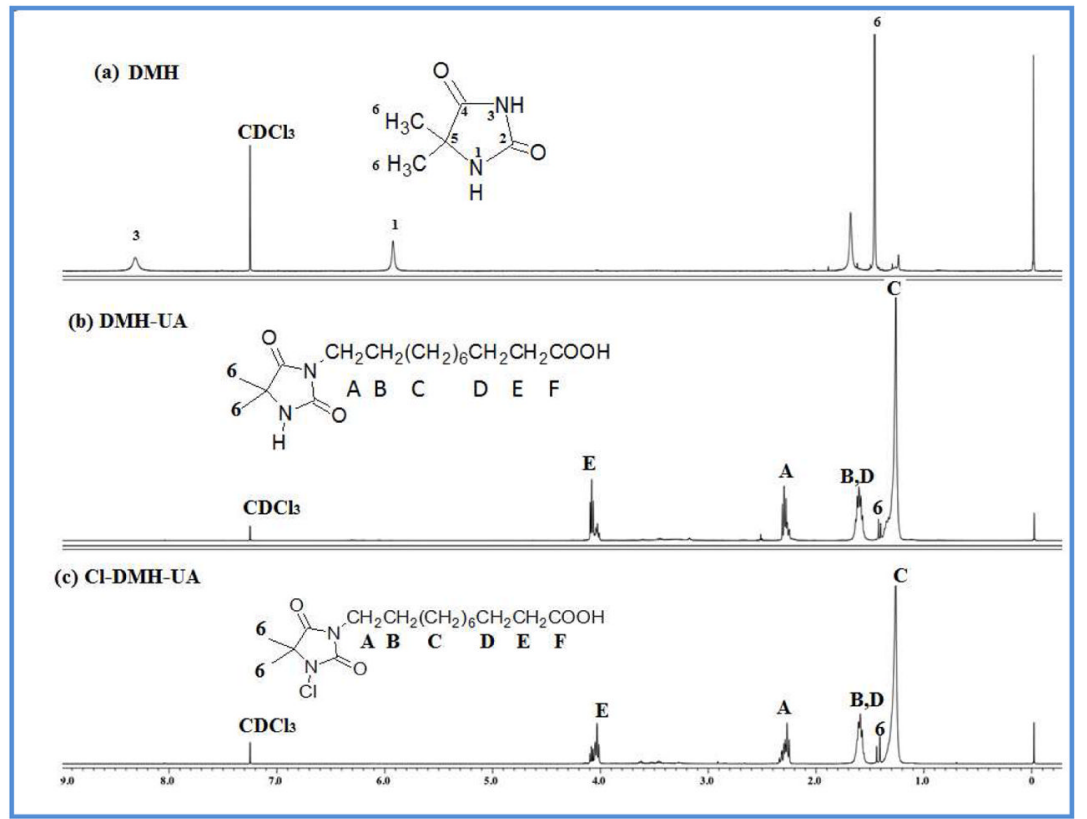

Figure 2.

${ }^{1} \mathrm{H}$ NMR spectra of (a) DMH, (b) DMH-UA, and (c) Cl-DMH-UA 


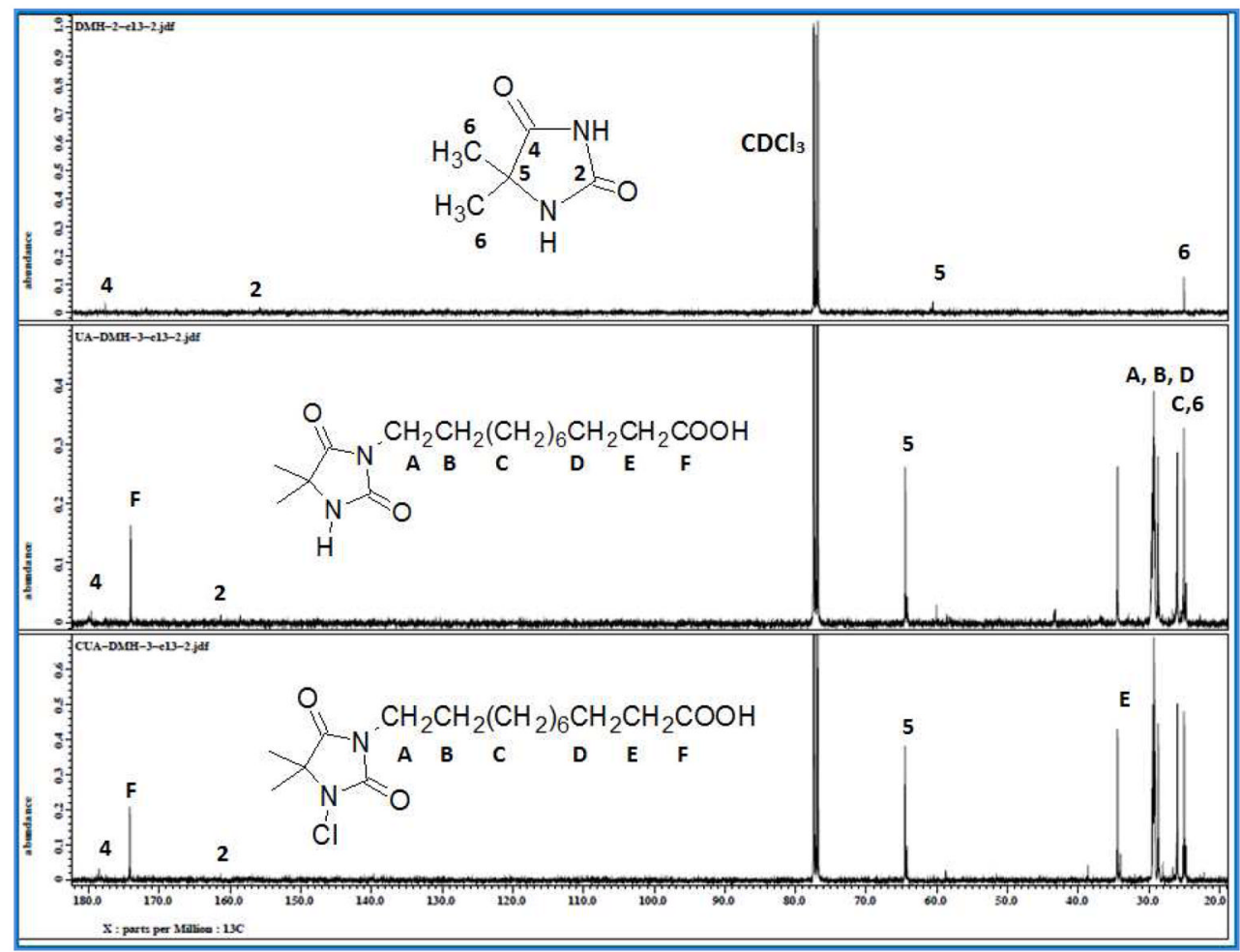

Figure 3.

${ }^{13} \mathrm{C}$ NMR spectra of (a) DMH, (b) DMH-UA, and (c) Cl-DMH-UA 


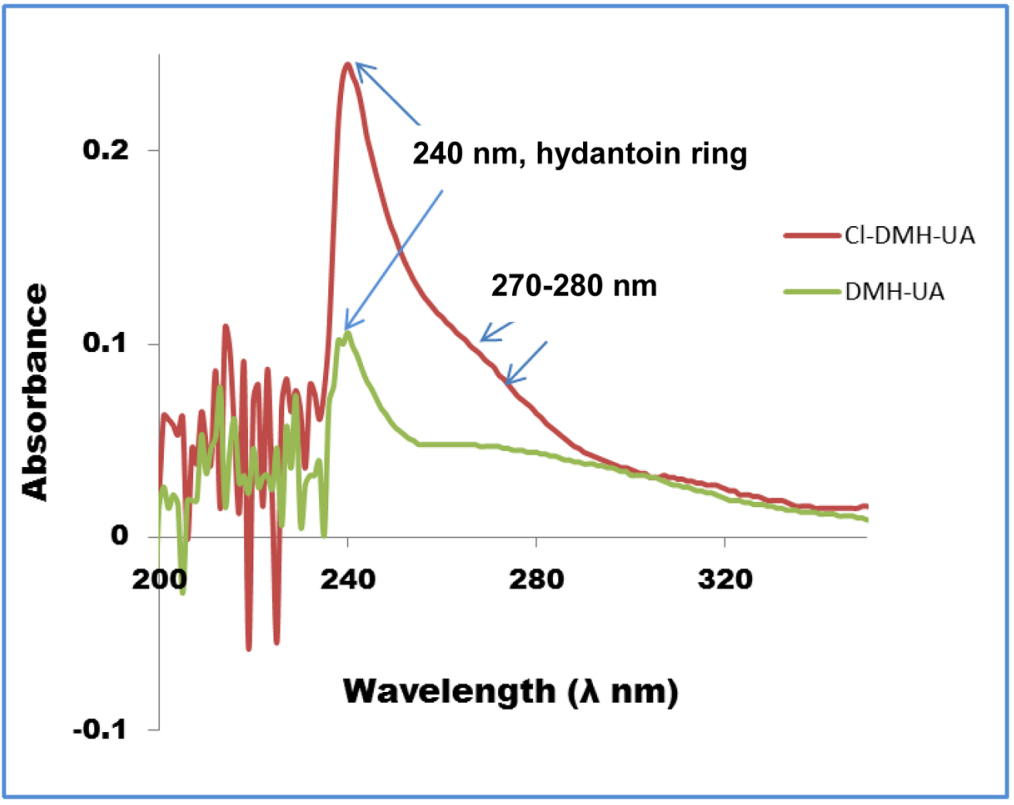

Figure 4.

UV spectra of DMH-UA and Cl-DMH-UA 


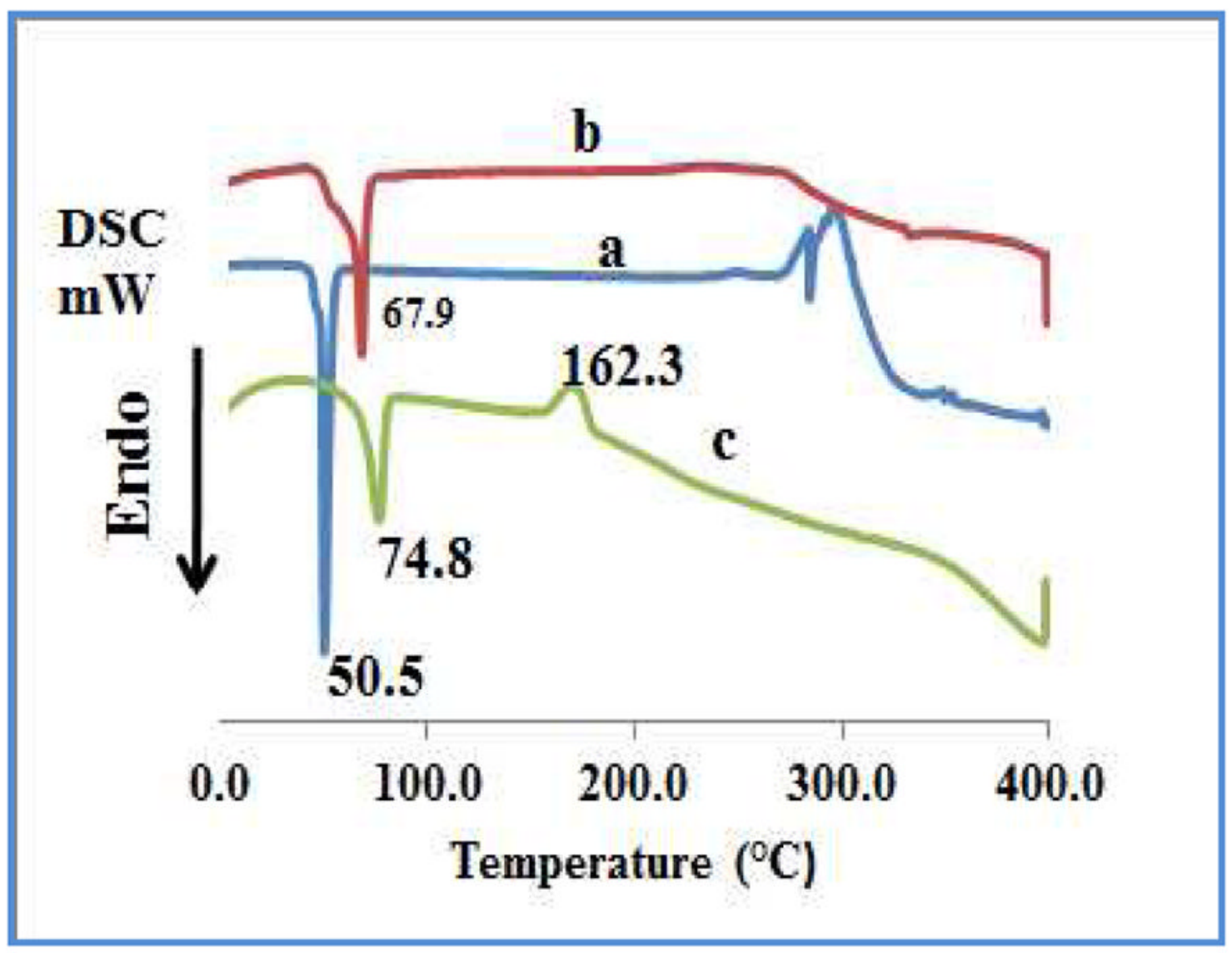

Figure 5.

DSC curves of (a) 11-bromo undecanoic acid, (b) DMH-UA, and (c) Cl-DMH-UA 


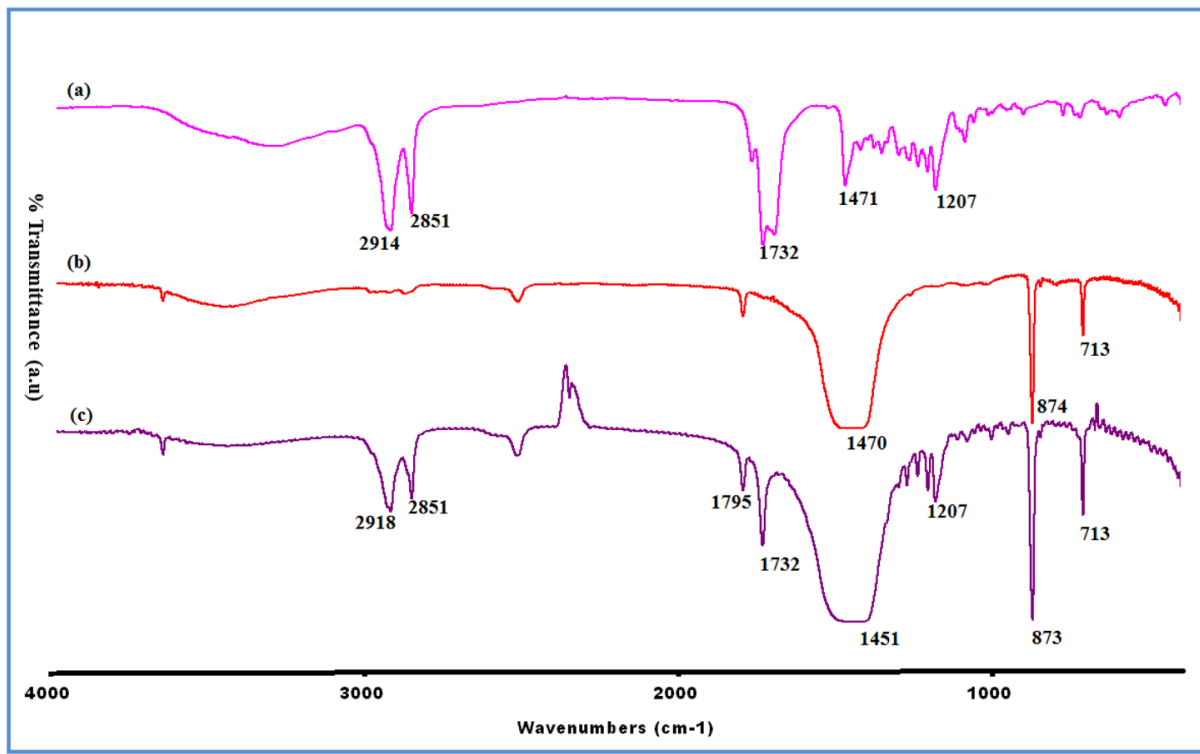

Figure 6.

FT-IR spectra of (a) Cl-DMH-UA, (b) unmodified $\mathrm{CaCO}_{3}$, and (c) Cl-DMH-UA-CaCO 3 . 


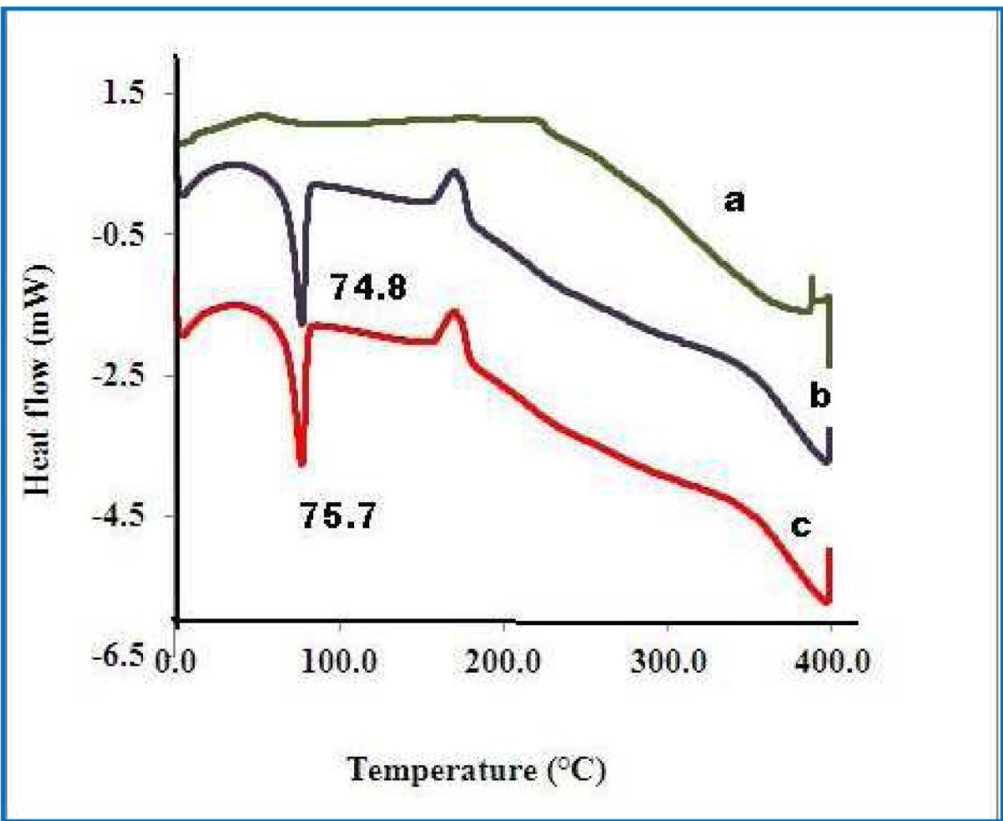

Figure 7.

DSC curves (a) untreated $\mathrm{CaCO}_{3}$ (b) Cl-DMH-UA and (c) Cl-DMH-UA-CaCO 3 

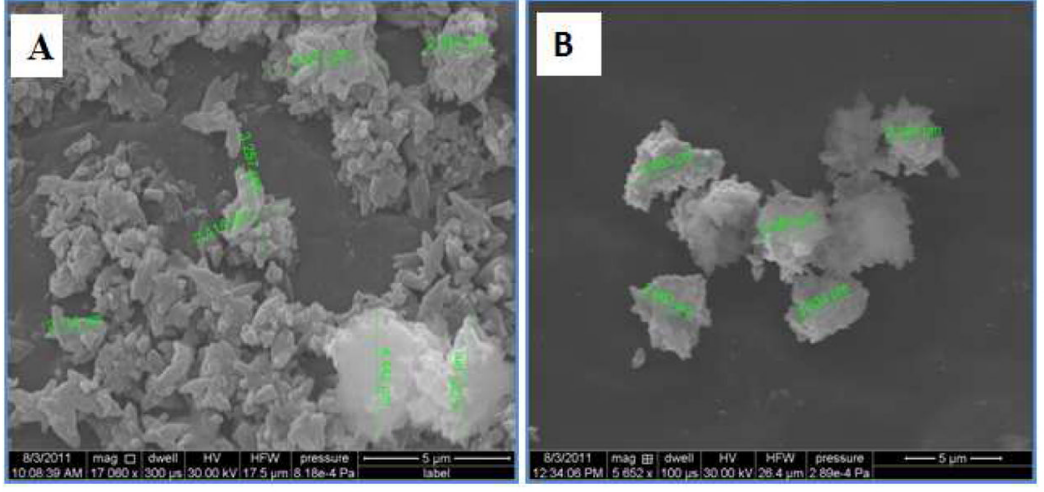

Figure 8.

SEM images of (A) unmodified $\mathrm{CaCO}_{3}$, and (B) Cl-DMH-UA-CaCO 3 

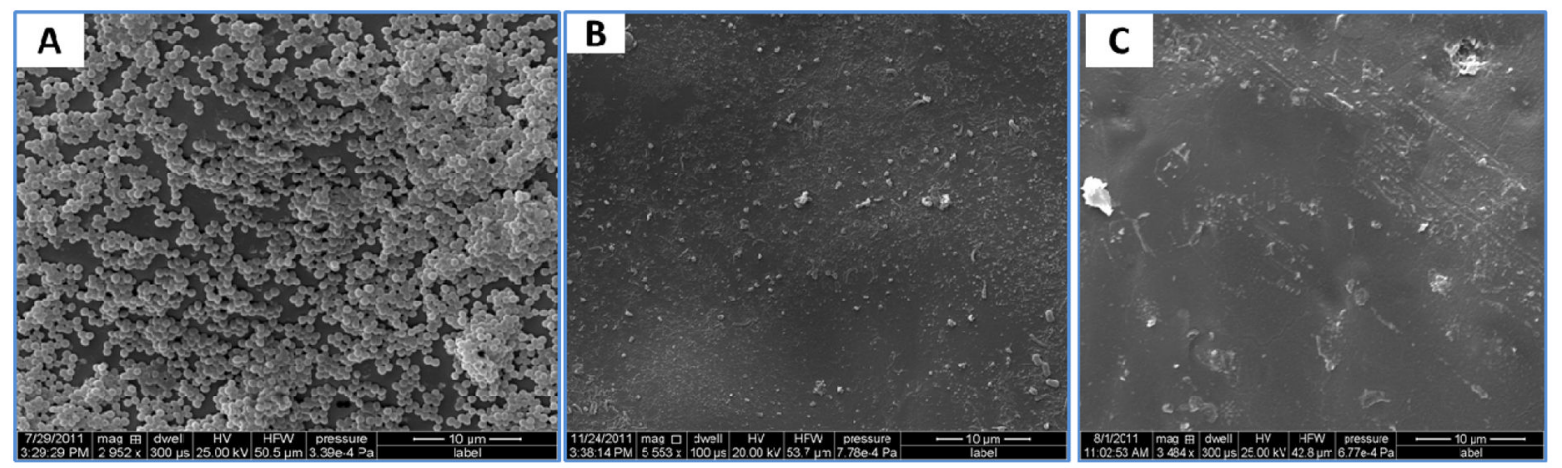

Figure 9.

SEM images of biofilm-controlling function against $S$. aureus of (A) Pure CA film as control, (B) CA film containing $5 \mathrm{wt} \%$ of Cl-DMH-UA, and (C) CA film containing 5 wt $\%$ of Cl-DMH-UA-CaCO 3 


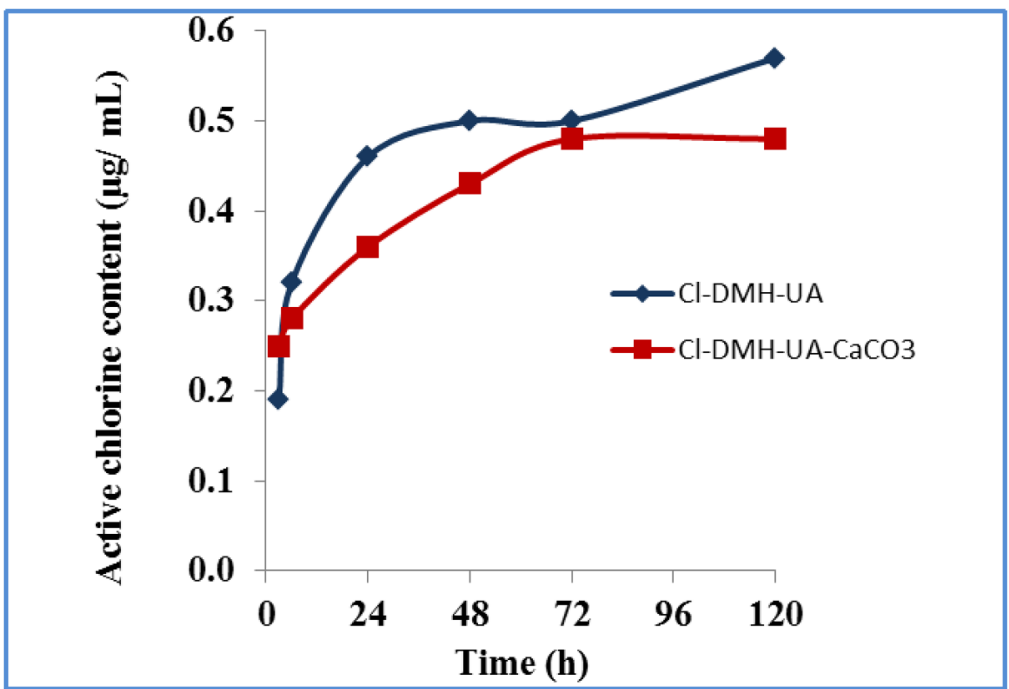

Figure 10.

Active chlorine level released into the immersing solution from CA films containing $5 \mathrm{wt} \%$ of Cl-DMH-UA and 5 wt \% of Cl-DMH-UA-CaCO 3 
<smiles>[Y]N1C(=O)NC(C)(C)C1=O</smiles>

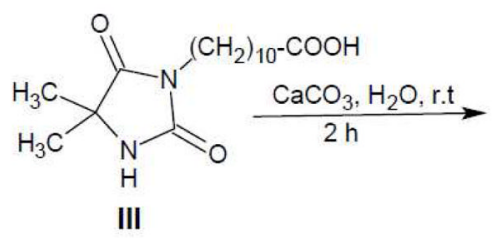

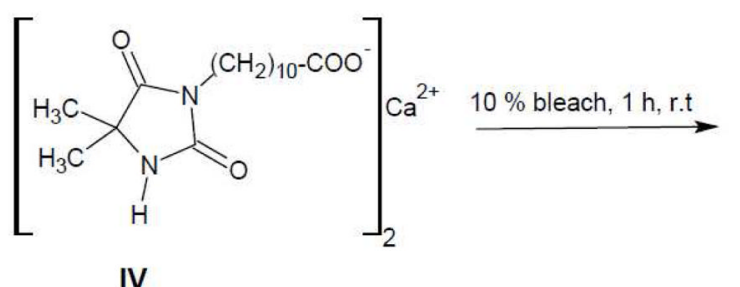<smiles>CC1(C)C(=O)N(CCC(=O)O)C(=O)N1Cl</smiles>

Scheme 1.

Synthesis of calcium salt of 3-chloro-4, 4-dimethyl hydantoin-undecanoate (Cl-DMH-UA$\left.\mathrm{CaCO}_{3}\right)$ 


\section{Table I}

Influences of active chlorine contents in Cl-DMH-UA or Cl-DMH-UA-CaCO 3 on percentage reduction of $10^{7}-10^{8} \mathrm{CFU} / \mathrm{mL}$ of $S$. aureus after $60 \mathrm{~min}$ and $120 \mathrm{~min}$ of contact *

\begin{tabular}{|c|c|c|c|c|}
\hline \multirow{2}{*}{ Active chlorine content } & \multicolumn{2}{|c|}{ Cl-DMH-UA } & \multicolumn{2}{c|}{ Cl-DMH-UA-CaCO } \\
\cline { 2 - 5 } & $\mathbf{6 0} \mathbf{~ m i n}$ & $\mathbf{1 2 0} \mathbf{~ m i n}$ & $\mathbf{6 0} \mathbf{~ m i n}$ & $\mathbf{1 2 0} \mathbf{~ m i n}$ \\
\hline $100 \mathrm{ppm}$ & $99.5 \%$ & $99.5 \%$ & $34 \%$ & $66 \%$ \\
\hline $300 \mathrm{ppm}$ & $99.9 \%$ & $100 \%$ & $39 \%$ & $94 \%$ \\
\hline $500 \mathrm{ppm}$ & $100 \%$ & $100 \%$ & $93 \%$ & $99.5 \%$ \\
\hline
\end{tabular}

* Cl-DMH-UA and Cl-DMH-UA-CaCO 3 were dispersed in water and made contact with the bacterial suspension. See text for details. 


\section{Table II}

Influences of Cl-DMH-UA or Cl-DMH-UA-CaCO 3 contents in CA films on percentage reduction of $10^{7}-10^{8}$ $\mathrm{CFU} / \mathrm{mL}$ of $S$. aureus and E. coli after 120 min of contact

\begin{tabular}{|c|c|c|c|c|}
\hline \multirow{2}{*}{ Additive content in CA } & \multicolumn{2}{|c|}{ Cl-DMH-UA } & \multicolumn{2}{c|}{ Cl-DMH-UA-CaCO } \\
\cline { 2 - 5 } & S. aureus & E. coli & S. aureus & E. coli \\
\hline $1 \mathrm{wt} \%$ & $98 \%$ & $95 \%$ & $95 \%$ & $66 \%$ \\
\hline $3 \mathrm{wt} \%$ & $99 \%$ & $99.9 \%$ & $99.9 \%$ & $73 \%$ \\
\hline $5 \mathrm{wt} \%$ & $99.9 \%$ & $100 \%$ & $100 \%$ & $100 \%$ \\
\hline
\end{tabular}

